\section{A Text-Book of Organic Chemistry}

Historical, Structural and Economic. By Prof. John Read. (Bell's Natural Science Series.) Third edition. Pp. xiv + 703. (London: G. Bell and Sons, Ltd., 1943.) 12s. $6 d$. net.

DROF. READ has taken advantage of yet another I reprinting of his deservedly popular book to keep the subject-matter abreast of current advances. Although the operation had to be effected without upsetting the pagination, considerable ingenuity has been exercised in the successful execution of this delicate task. Without such restrictions the author would undoubtedly have made extensive alterations and additions, as a piecemeal revision of this type can never be entirely satisfactory. It is therefore not difficult for the reviewer to direct attention to a number of desirable additions and deletions, although it may be somewhat unfair in the circumstances. In particular, some mention of crotonaldehyde and the ethanolamines, both of which combine theoretical with industrial interest, might have been made; less emphasis could have been given to wood distillation as an industrial process, and the fact that a number of sex hormones have now been isolated and their structures determined could have been noted. In view of recent developments in the United States, it is unfortunate that the expression "the nitroparaffins have little practical importance" should have been allowed to remain. It might be pointed out that vitamin A has now been obtained in crystalline form and that the vitamins of the $B, E$ and $K$ groups are sufficiently well characterized to deserve passing mention.

None of these umissions, however, detracts seriously from the unquestionable value of this fascinating treatment of organic chemistry. On the contrary, the useful revision of the sections on petroleum and the electronic theory of valency, the latter including some discussion of resonance concepts, the inclusion of a modern formula for a polysaccharide and references to sulphanilamide, $M$ and $B 693$ and to the electrophoresis of proteins, to mention just a few points, combine effectively to bring this reprinting up to date. E. R. H. JoNes.

\section{Intermediate Chemistry}

By Prof. T. M. Lowry and A. C. Cavell. Third edition. Pp. xvi+876. (London: Macmillan and Co., Ltd., I942.) 12s. $6 d$.

TIRST published in 1936 , and revised in 1938, this 4 excellent book has again been brought up to date by alterations in several important sections-in particular those dealing with carbon monoxide, the rusting of iron, the distillation of liquids, organic analysis, and the organic derivatives of ammonia. Many additional numerical problems have been provided, and improvements in the experimental sections -nearly two hundred of them-have been introduced.

Its purpose being "to provide a complete text-book of chemistry for Intermediate and Higher School Certificate examinations", the volume is accordingly divided into six parts, headed, respectively, general and theoretical, typical elements, transitional elements, analysis, physical chemistry, and principles of organic chemistry. True, a candidate for one of these examinations who had fully mastered its content would be remarkably well prepared; but wise teachers who tolerate examinations, and conscientious students who utilize them, are likely to discern in this very circumstance the real aim of the authors. This, quite evidently, is not merely to elongate any pass list, but to help to lay a solid foundation of accurate chemical knowledge and intelligent appreciation; a foundation which retains familiarity of design while providing truly adequate footings for the support of a necessarily weighty building in the modern fashion. Though described as an examination text-book, therefore, it is not a cram book. Indeed the authors, when discussing the habit of the individual trees, frequently direct attention to one or other aspect of the wood; and this serves to promote a balanced view and to maintain a sense of orderliness which contributes much to the reader's interest and holds his attention.

\section{Chemical Industries}

Edited by L. Ivanovszky. Eighteenth edition, largely rewritten and revised. Pp. xxiv +360 . (London: Leonard Hill, Ltd., 1943.) 15s.

T $T$ would be difficult to arrange the experimental 1 sciences in an order that would tally with their relative importance in everyday life, but chemistry would undoubtedly occupy a very high place. Far away and long ago their applications played a very minor part; here and to-day they are almost indispensable. It is true that these applications relate very largely to the material side of our daily life, but unless we go forward with the march of civilization, look to increasing our wants as well as our needs, and extending our comforts, we shall fall behind as a progressive people and sink into the limbo of the 'have been'. These reflexions arise from a perusal of the latest edition of Leonard Hill's "Chemical Industries", which is replete with the information required by manufacturers, merchants, consumers, and by those numerous 'impure' chemists who traffic in the applications of their science to material human wants. This new edition is considerably larger than the old, The glossary of industrial chemicals has been increased by more than one half; the tables of physical and chemical constants have been revised and extended, and many new data concerning organic and inorganic compounds have been added. Further, entirely new subsections are incorporated dealing with metals and alloys, nonmetallic materials, chemical plant and instruments, and the older ones on pharmaceuticals and perfumery raw materials have been replaced by new. Power plant, water-treatment, handling, conveying and transport are other sections of this very useful compilation.

E. H. T.

\section{A System of Qualitative Inorganic Analysis}

By Dr. J. L. B. Smith. Second edition. Pp. viii +64 . (Cape Town, Bloemfontein and Port Elizabeth : Nasionale Pers Beperk, 1943.) 4s. $6 d$.

$T$ HIS work on qualitative analysis is intended purely as a laboratory manual, since the physicochemical principles underlying analysis are not dis. cussed and very little is said about the nature of the chemical reactions involved in the tests. These omissions, together with the use of a very large number of abbreviations, give the text rather a forbidding appearance, and the reader the impression that qualitative analysis is purely a mechanical operation of adding so much of one substance to so much of another. The book, however, contains some notable features which deserve consideration by students of advanced chemistry. Thus a systematic scheme has been worked out for the detection of all the common anions, and very precise details have 